\title{
Precise synthesis of poly(1-adamantyl methacrylate) by atom transfer radical polymerization
}

\author{
Keita Fuchise ${ }^{1}$, Masako Sone ${ }^{1}$, Yutaka Miura ${ }^{1}$, Ryosuke Sakai $^{1}$, Atsushi Narumi ${ }^{2}$, Shin-Ichiro Sato ${ }^{1}$, \\ Toshifumi Satoh ${ }^{1}$ and Toyoji Kakuchi ${ }^{1}$
}

1-Adamantyl methacrylate (AdMA) was polymerized using the atom transfer radical polymerization (ATRP) method with methyl $\alpha$-bromoisobutyrate (MBiB), copper(I) bromide (CuBr), copper(II) bromide $\left(\mathrm{CuBr}_{2}\right)$ and 1,1,4,7,10,10-hexamethyltriethylenetetramine (HMTETA) in toluene at $60^{\circ} \mathrm{C}$, producing well-defined poly(1-adamantyl methacrylate) (PAdMA). Simultaneous control of the molecular weight and tacticity of PAdMA was successfully achieved by the ATRP method using the $\mathrm{MBiB} / \mathrm{CuBr} / \mathrm{CuBr}_{2} /$ tris[2-(dimethylamino)ethyl]amine-initiating system in 1,1,1,3,3,3-hexafluoro-2-propanol (HFIP) at $-20^{\circ} \mathrm{C}$. Block copolymerization of AdMA and methyl methacrylate (MMA) was successfully achieved by the poly(methyl methacrylate) macroinitiator/ $\mathrm{CuBr}_{2} / \mathrm{HMTETA} / \mathrm{in}$ (II) 2-ethylhexanoate-initiating system based on activators generated by electron transfer (AGET) ATRP method. Differential scanning calorimetry revealed the relationship between the glass transition temperature, molecular weight and tacticity of the obtained PAdMA. Polymer Journal (2010) 42, 626-631; doi:10.1038/pj.2010.55; published online 30 June 2010

Keywords: atom transfer radical polymerization (ATRP); activators generated by electron transfer (AGET); adamantyl group; block copolymerization; tacticity; glass transition temperature

\section{INTRODUCTION}

Various poly(meth)acrylates bearing bulky ester groups, such as bornyl, ${ }^{1}$ isobornyl, ${ }^{1-3}$ adamantyl ${ }^{4-7}$ and its derivatives, ${ }^{4-6,8-11}$ have been synthesized to improve the thermal properties, such as the glass transition temperature and the thermal degradation temperature, of poly(methyl methacrylate) (PMMA). For example, the incorporation of adamantyl groups into polymer structures generally produces not only a high thermal stability but also an improvement in other physical and chemical properties, such as transparency to ultraviolet light, low dielectric constant, hydrophobicity, high oxidation resistance, low surface energy and high density. Although these characteristics are interesting, there are only few studies on the synthesis of poly(1-adamantyl methacrylate) (PAdMA); Otsu and colleagues ${ }^{5}$ reported the conventional radical polymerization of 1-adamantyl methacrylate (AdMA) and its kinetic properties, and Nakahama and colleagues ${ }^{4}$ reported the living anionic polymerization of AdMA leading to well-defined PAdMA.

Controlled/living radical polymerizations, such as nitroxide-mediated radical polymerization, atom transfer radical polymerization (ATRP) and reversible addition-fragmentation chain transfer polymerization, have been applied to various methacrylate monomers. ${ }^{12-14}$ The controlled/living radical polymerization of methacrylate monomers bearing bulky ester groups, such as AdMA, which guarantees the generation of well-defined macromolecular architectures such as the block copolymer, graft copolymer and star-shaped polymer on a preparative scale, is still of great interest. In addition, we have previously reported that the simultaneous control of the molecular weight and stereochemistry ${ }^{15}$ of PMMA was accomplished using the designed initiating system based on ATRP. ${ }^{16,17}$ Therefore, it is interesting to expand our method to methacrylates bearing bulky group, such as AdMA.

We now report the polymerization of AdMA using the ATRPinitiating system, methyl $\alpha$-bromoisobutyrate (MBiB) and copper(I) bromide $(\mathrm{CuBr})$ with 1,1,4,7,10,10-hexamethyltriethylenetetramine (HMTETA), 2,2'-bipyridyl (bpy) and tris[2-(dimethylamino)ethyl] amine (Me ${ }_{6}$ TREN), as shown in Scheme 1. The livingness of the ATRP of AdMA is confirmed through a kinetic investigation using the $\mathrm{CuBr} /$ $\mathrm{CuBr}_{2} / \mathrm{HMTETA}$-initiating system, and the stereocontrol of the ATRP of AdMA is carried out using the $\mathrm{CuBr} / \mathrm{CuBr}_{2} / \mathrm{Me}_{6} \mathrm{TREN}$-initiating system in a fluorinated solvent. Poly(methyl methacrylate)-block-poly(1-adamantyl methacrylate) (PMMA- $b$-PAdMA) was prepared by the ATRP of AdMA using the PMMA macroinitiator, PMMA-Br, as shown in Scheme 2. The effects of the molecular weight and tacticity of the well-defined PAdMAs on glass transition temperature are discussed.

\section{MATERIALS AND METHODS}

Materials

Copper(I) bromide (CuBr, 99.999\%), copper(II) bromide $\left(\mathrm{CuBr}_{2}, 99.999 \%\right)$ and HMTETA $(>97 \%)$ were purchased from Sigma-Aldrich Chemicals Co.

${ }^{1}$ Division of Biotechnology and Macromolecular Chemistry, Graduate School of Engineering, Hokkaido University, Sapporo, Japan and ${ }^{2}$ Department of Polymer Science and Engineering, Graduate School of Science and Engineering, Yamagata University, Yonezawa, Japan

Correspondence: Professor T Kakuchi, Division of Biotechnology and Macromolecular Chemistry, Graduate School of Engineering, Hokkaido University, N13W8, Kita-ku, Sapporo 060-8628, Japan.

E-mail: kakuchi@poly-bm.eng.hokudai.ac.jp

Received 7 April 2010; revised 1 May 2010; accepted 2 May 2010; published online 30 June 2010 

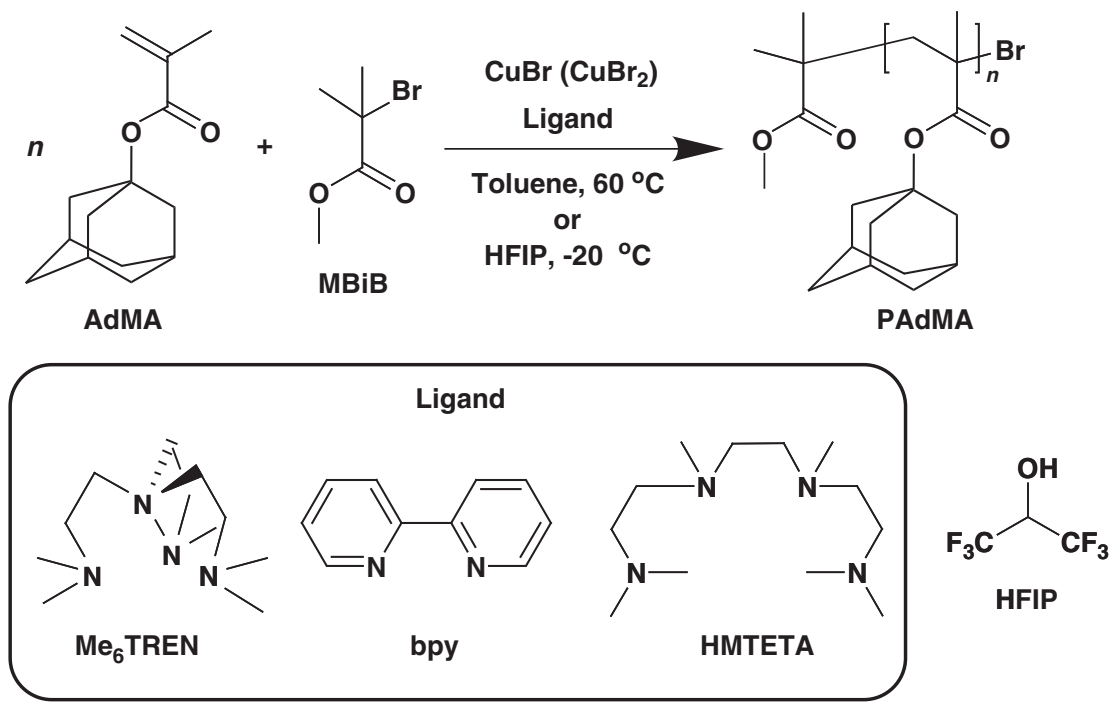

Scheme 1 ATRP of 1-Adamantyl methacrylate (AdMA).

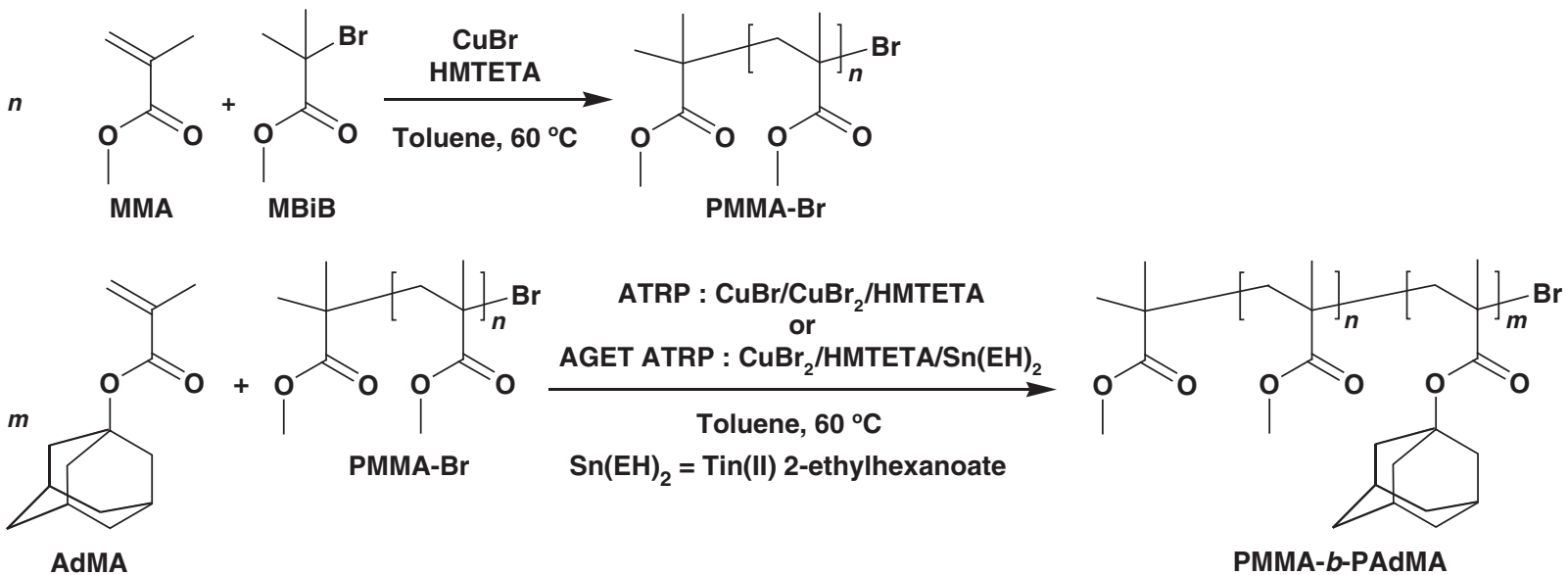

Scheme 2 Synthesis of poly(methyl methacrylate) macroinitiator (PMMA-Br) and poly(methyl methacrylate)-block-poly(1-adamantyl methacrylate) (PMMA-bPAdMA).

(St Louis, MO, USA) Me 6 TREN was supplied by Mitsubishi Chemical Co. Ltd. (Tokyo, Japan) HMTETA and $\mathrm{Me}_{6}$ TREN were purified by distillation over $\mathrm{CaH}_{2}$ under reduced pressure. AdMA was donated by Idemitsu Kosan Co. Ltd. (Tokyo, Japan) and distilled over $\mathrm{CaH}_{2}$ and $\mathrm{CuBr}_{2}$ under argon. bpy was purchased from Merck KGaA (Darmstadt, Germany) and purified by recrystallization from hexane. MBiB was purchased from Fluka (Buchs, Switzerland) and distilled over $\mathrm{CaH}_{2}$ under argon before use. Dry toluene (>99.5\%; water content, $<0.001 \%$ ) was purchased from Kanto Chemicals Co. Inc. (Tokyo, Japan) and was used as received. Tin(II) 2-ethylhexanoate $\left(\mathrm{Sn}(\mathrm{EH})_{2}\right)$ was purchased from Wako Pure Chemical Industries Ltd. (Osaka, Japan) and was used as received. 1,1,1,3,3,3-hexafluoro-2-propanol (HFIP) was supplied by Central Glass Co. Ltd. (Tokyo, Japan) and was distilled from $\mathrm{CaH}_{2}$ under argon.

\section{Measurements}

The polymerization solution was prepared in an MBRAUN stainless steel glovebox (MBRAUN, Garching, Germany) equipped with a gas purification system (molecular sieves and copper catalyst) under a dry argon atmosphere $\left(\mathrm{H}_{2} \mathrm{O}, \mathrm{O}_{2}<1\right.$ p.p.m.). The moisture and oxygen contents in the glovebox were monitored by MB-MO-SE 1 and MB-OX-SE 1 , respectively. ${ }^{1} \mathrm{H}(400 \mathrm{MHz})$ and ${ }^{13} \mathrm{C}(100 \mathrm{MHz}) \mathrm{NMR}$ spectra were recorded using a JEOL JNM-A400II (JEOL, Akishima, Japan). Size exclusion chromatography (SEC) was performed at $40{ }^{\circ} \mathrm{C}$ in chloroform $\left(0.8 \mathrm{ml} \mathrm{min}^{-1}\right)$ by a Jasco GPC-900 system (Jasco, Hachioji, Japan) equipped with a Tosoh $\mathrm{TSK}_{\mathrm{gel}} \mathrm{GMH}_{\mathrm{HR}} \mathrm{M}$ column (Tosoh, Tokyo, Japan) (linear; $7.8 \mathrm{~mm} \times 300 \mathrm{~mm}$; pore size $=16 \mathrm{~nm}$; bead size $=5 \mu \mathrm{m}$; exclusion limit$4 \times 10^{6}$ ), Shodex KF-804L columns (linear; $8 \mathrm{~mm} \times 300 \mathrm{~mm}$; pore size $=20 \mathrm{~nm}$; bead size $=7 \mu \mathrm{m}$; exclusion limit $\left.=4 \times 10^{5}\right)$ and a refractive index detector. The number-average molecular weight $\left(M_{\mathrm{n}}\right)$ and polydispersity index $\left(M_{\mathrm{w}} / M_{\mathrm{n}}\right)$ of the polymers were calculated on the basis of PMMA calibration. The monomer conversion in the polymerization was calculated from the concentration of the residual monomer in the reaction mixture, as determined by a Shimadzu GC17A gas chromatography (GC) system (Shimadzu, Kyoto, Japan) equipped with an SGE BPX70 capillary column (SGE, Ringwood, Australia) $(30 \mathrm{~m} \times 0.25 \mathrm{~mm}$; film thickness, $0.25 \mu \mathrm{m}$; temperature, $120^{\circ} \mathrm{C}$ ) and an flame ionization detector (temperature, $120^{\circ} \mathrm{C}$ ) using toluene or HFIP internal standards. The inversegated decoupling ${ }^{13} \mathrm{C}$ NMR spectra for the tacticity analysis of PAdMA were measured using a $20 \%(\mathrm{w} / \mathrm{v})$ sample in $\mathrm{CDCl}_{3}$ at $55^{\circ} \mathrm{C}$ with a $45^{\circ}$ pulse angle, 7.0 s delay of the inverse-gated decoupling and 10000 scans. The triad tacticity of a PAdMA molecule was determined from the integral values of the quaternary carbon on an adamantyl group of the polymer in the ${ }^{13} \mathrm{C}$ NMR spectrum. The glass transition temperature $\left(T_{\mathrm{g}}\right)$ of the polymers was measured by Differential scanning calorimetry (DSC) using Seiko Instruments SSC 5200 DSC 220 (Seiko, Chiba, Japan). Samples in 3-10 mg portions were first heated above their $T_{\mathrm{g}}$ at a heating rate of $10^{\circ} \mathrm{Cmin}^{-1}$, then cooled to $-20{ }^{\circ} \mathrm{C}$ at a cooling rate of $40^{\circ} \mathrm{C} \mathrm{min}^{-1}$. The samples were reheated to $280^{\circ} \mathrm{C}$ at a heating rate of $10^{\circ} \mathrm{Cmin}^{-1}$. All $T_{\mathrm{g}}$ values were obtained from the second scan after removing the thermal history. 


\section{Polymerization of AdMA}

A typical procedure for the polymerization is as follows: $\mathrm{MBiB}(5.88 \mu \mathrm{l}$, $45.4 \mu \mathrm{mol})$ was added to a solution of AdMA $(1.00 \mathrm{~g}, 4.54 \mathrm{mmol}), \mathrm{CuBr}$ ( $6.5 \mathrm{mg}, 45 \mu \mathrm{mol})$ and HMTETA $(10.6 \mathrm{mg}, 45.4 \mu \mathrm{mol})$ in toluene $(3 \mathrm{ml})$ under argon. Polymerization was initiated by heating at $60^{\circ} \mathrm{C}$. After $9 \mathrm{~h}$, the reaction mixture was exposed to air to quench the polymerization. The product was passed through an alumina column using toluene as the eluent to remove the copper catalyst, followed by two reprecipitations in a mixed solvent of methanol and water $(1 / 1, \mathrm{v} / \mathrm{v})$. The purified polymer was obtained as a white powder. The reaction yield was $0.475 \mathrm{~g}(47.1 \%)$, conversion was $57.0 \%, M_{\mathrm{n}}$ was $8.3 \mathrm{~kg} \mathrm{~mol}^{-1}$ and $M_{\mathrm{w}} / M_{\mathrm{n}}$ was 1.13 . Polymerizations using the other ligands, solvent and additional $\mathrm{CuBr}_{2}$ were conducted using a similar procedure.

Block copolymerization of AdMA with poly(methyl methacrylate) macroinitiator

The procedure for the preparation of the poly(methyl methacrylate) macroinitiator (PMMA-Br) in toluene at $60^{\circ} \mathrm{C}$ is the same procedure used for the polymerization of AdMA. The amounts of the necessary reagents are shown as follows: MMA (22.7 g, $227 \mathrm{mmol}), \mathrm{MBiB}(0.294 \mu \mathrm{l}, 2.27 \mathrm{mmol}), \mathrm{CuBr}(325 \mathrm{mg}$, $2.27 \mathrm{mmol})$, HMTETA $(525 \mathrm{mg}, 2.28 \mathrm{mmol}$ ) and toluene (50 ml). The PMMA macroinitiator (PMMA-Br) was obtained as a white powder. The reaction yield was $8.96 \mathrm{~g}(38.8 \%)$, conversion was $45.1 \%, M_{\mathrm{n}}$ was $9.9 \mathrm{~kg} \mathrm{~mol}^{-1}$ and $M_{\mathrm{w}} / M_{\mathrm{n}}$ was 1.15 .

Block copolymerization of AdMA and MMA using the $\mathrm{CuBr} / \mathrm{CuBr}_{2} /$ HMTETA catalytic system was carried out by the following procedure: a stock solution of HMTETA $(5.1 \mathrm{mg}, 22 \mu \mathrm{mol}), \mathrm{CuBr}(2.6 \mathrm{mg}, 18 \mu \mathrm{mol})$ and $\mathrm{CuBr}_{2}$ $(0.8 \mathrm{mg}, 4 \mu \mathrm{mol})$ in toluene $(0.16 \mathrm{ml})$ was added to a solution of PMMA-Br $(242 \mathrm{mg}, 24.4 \mu \mathrm{mol})$ and AdMA $(0.407 \mathrm{~g}, 1.85 \mathrm{mmol})$ in toluene $(1.46 \mathrm{ml})$ under argon. Polymerization was initiated by heating at $60^{\circ} \mathrm{C}$. After $9 \mathrm{~h}$, the reaction mixture was exposed to air to quench the polymerization. The subsequent purification procedure was the same as that for PAdMA. PMMA$b$-PAdMA was obtained as a white powder. The reaction yield was $170.2 \mathrm{mg}$, conversion was $24.7 \%, M_{\mathrm{n}}$ was $15.5 \mathrm{~kg} \mathrm{~mol}^{-1}$ and $M_{\mathrm{w}} / M_{\mathrm{n}}$ was 1.18 .

The block copolymerization of AdMA and MMA using the $\mathrm{CuBr}_{2} / \mathrm{HMTE}-$ $\mathrm{TA} / \mathrm{Sn}(\mathrm{EH})_{2}$ catalytic system was carried out using the following procedures: $\mathrm{Sn}(\mathrm{EH})_{2}(8.3 \mathrm{mg}, 20.5 \mu \mathrm{mol})$ was added to a solution of PMMA-Br $(629 \mathrm{mg}$, $62.6 \mu \mathrm{mol})$, AdMA $(1.00 \mathrm{~g}, 4.54 \mathrm{mmol}), \mathrm{CuBr}_{2}(10.2 \mathrm{mg}, 45.7 \mu \mathrm{mol})$ and HMTETA $(10.5 \mathrm{mg}, 45.6 \mu \mathrm{mol})$ in toluene $(3.00 \mathrm{ml})$ under argon to initiate polymerization by heating at $60^{\circ} \mathrm{C}$. After $2 \mathrm{~h}$, the reaction mixture was exposed to air to quench the polymerization. The subsequent purification procedure was the same as that for PAdMA. PMMA- $b$-PAdMA was obtained as a white powder. The yield was $1.17 \mathrm{~g}$, conversion was $42.4 \%, M_{\mathrm{n}}$ was $18.7 \mathrm{~kg} \mathrm{~mol}^{-1}$ and $M_{\mathrm{w}} / M_{\mathrm{n}}$ was 1.13 .

\section{RESULTS AND DISCUSSION}

Atom transfer radical polymerization of 1-adamantyl methacrylate We first carried out the polymerization of AdMA in toluene at $60^{\circ} \mathrm{C}$ for $9 \mathrm{~h}$ using $\mathrm{MBiB}$, copper(I) bromide $(\mathrm{CuBr})$ and an amine ligand $\left([\mathrm{AdMA}]_{0} /[\mathrm{MBiB}]_{0}=100 / 1\right)$. The proper choice of ligand for copper is necessary to control the ATRP. Thus, three ligands, $\mathrm{Me}_{6}$ TREN, bpy and HMTETA, were used to optimize the polymerization conditions (Scheme 1). Table 1 summarizes the results of the polymerizations, and Figure 1 shows the SEC traces of the obtained polymers. The $\mathrm{CuBr} / \mathrm{Me}_{6}$ TREN catalytic system (Table 1, run 1) produced an uncontrolled polymerization, which resulted in PAdMA having an $M_{\mathrm{n}}$ of $16.4 \mathrm{~kg} \mathrm{~mol}^{-1}$, a bimodal molecular weight distribution and $M_{\mathrm{w}} / M_{\mathrm{n}}$ of 2.34 . Although the polymerization using the $\mathrm{CuBr} / \mathrm{bpy}$ catalytic system (Table 1, run 2) produced PAdMA with a unimodal molecular weight distribution, the $M_{\mathrm{w}} / M_{\mathrm{n}}$ of the obtained PAdMA was still as high as 1.35. However, polymerization using the $\mathrm{CuBr} / \mathrm{HMTETA}$ catalytic system (Table 1, run 3) produced the narrow-dispersed PAdMA with an $M_{\mathrm{n}}$ of $8.3 \mathrm{~kg} \mathrm{~mol}^{-1}$ and an $M_{\mathrm{w}} / M_{\mathrm{n}}$ of 1.13 . However, the $M_{\mathrm{n}}$ value of the obtained PAdMA was lower than the theoretical
Table 1 Atom transfer radical polymerization of AdMA using the $\mathrm{MBiB} / \mathrm{CuBr}$-initiating system with $\mathrm{Me}_{6}$ TREN, bpy and HMTETA

\begin{tabular}{|c|c|c|c|c|c|c|c|}
\hline \multirow[b]{2}{*}{ Run } & \multirow[b]{2}{*}{ Ligand } & \multirow[b]{2}{*}[\mathrm{CuBr}]{$_{O} /[\text { ligand }]_{O}$} & \multirow[b]{2}{*}{ Time (h) } & \multirow[b]{2}{*}{ Conv. $(\%)^{a}$} & \multicolumn{2}{|c|}{$\mathrm{M}_{n}\left(\mathrm{~kg} \mathrm{~mol}^{-1}\right)$} & \multirow[b]{2}{*}{$\mathrm{M}_{w} \mathrm{M}_{n}^{\mathrm{b}}$} \\
\hline & & & & & Theo. ${ }^{\mathrm{c}}$ & Obsd. ${ }^{\mathrm{b}}$ & \\
\hline 1 & $\mathrm{Me}_{6}$ TREN & $1 / 1$ & 9.0 & 55.1 & 12.3 & 16.4 & 2.37 \\
\hline 2 & bpy & $1 / 2$ & 9.0 & 55.5 & 12.4 & 18.9 & 1.35 \\
\hline 3 & HMTETA & $1 / 1$ & 9.0 & 57.0 & 12.7 & 8.3 & 1.13 \\
\hline $4^{d}$ & HMTETA & $1 / 1$ & 8.5 & 48.5 & 10.9 & 10.9 & 1.08 \\
\hline
\end{tabular}

Solvent, toluene; temp., $60^{\circ} \mathrm{C}$; $[\mathrm{AdMA}]_{0} /[\mathrm{MBiB}]_{0} /[\mathrm{CuBr}]_{0}=100 / 1 / 1$; $[\mathrm{AdMA}]_{0}=1.14 \mathrm{moll}^{-1}$. aDetermined by GC from the concentration of the residual monomer with toluene as the internal standard.

standard.
betermined by SEC using PMMA standards in $\mathrm{CHCl}_{3}$.

${ }^{c}$ Calculated from $[\mathrm{AdMA}]_{0} /[\mathrm{MBiB}]_{0} \times$ conv. $\times(\mathrm{MW}$ of $\mathrm{AdMA}=220.31)+(\mathrm{MW}$ of $\mathrm{MBiB}=181.03)$.

${ }^{d} 0.2$ equivalent of $\mathrm{CuBr}_{2}$ was added to the reaction mixture.

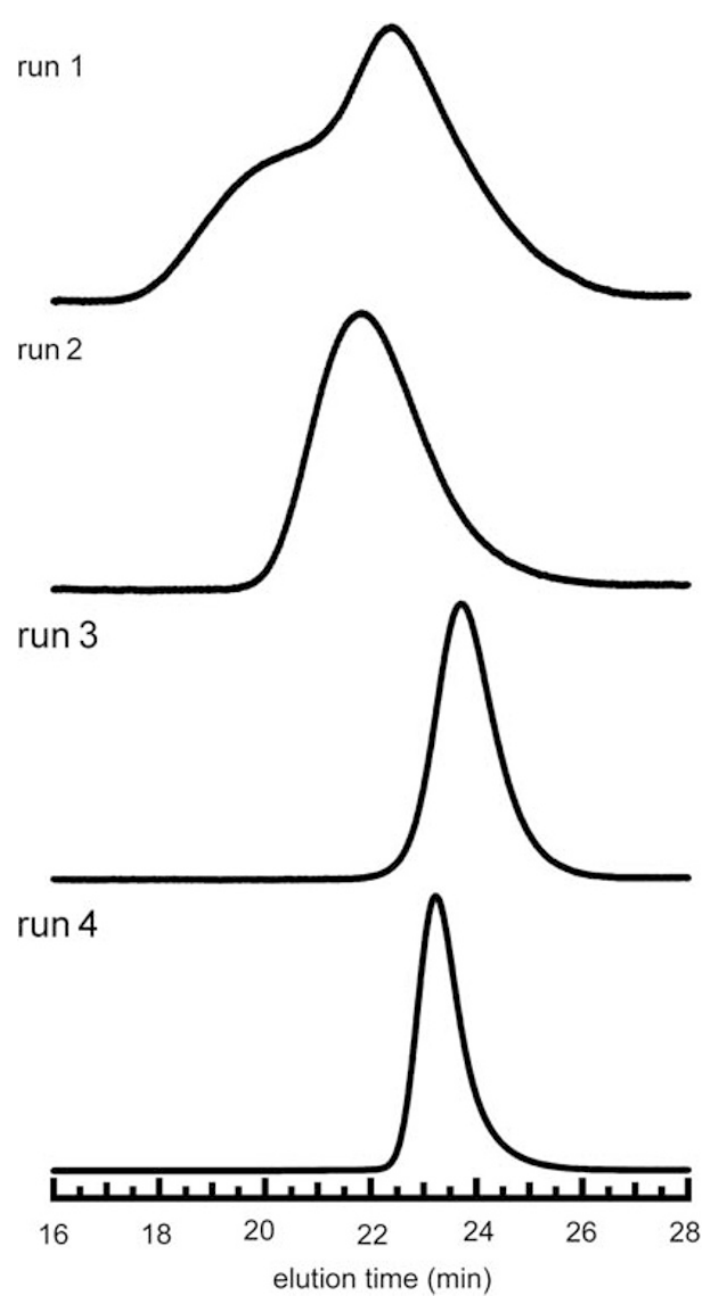

Figure 1 SEC traces of PAdMA prepared by ATRP at $60^{\circ} \mathrm{C}$ in toluene using $\mathrm{CuBr} / \mathrm{Me}_{6}$ TREN (run 1), CuBr/bpy (run 2), CuBr/HMTETA (run 3) and $\mathrm{CuBr}$ / $\mathrm{CuBr}_{2} / \mathrm{HMTETA}$ (run 4) as the catalytic system.

molecular weight $\left(M_{\mathrm{n} \text {,theo. }}\right)$ of $12.7 \mathrm{~kg} \mathrm{~mol}^{-1}$ predicted from the monomer conversion and the initial ratio of AdMA and MBiB. Therefore, we carried out an additional AdMA polymerization using the $\mathrm{CuBr} /$ copper(II) bromide $\left(\mathrm{CuBr}_{2}\right)$ /HMTETA catalytic system in toluene at $60^{\circ} \mathrm{C}$ for $8.5 \mathrm{~h}$ (Table 1 , run 4 ). It is well known that the 
addition of copper(II) species to an ATRP system using a copper(I) catalyst provides good control of the molecular weight. ${ }^{18,19}$ After polymerization, the $M_{\mathrm{n}}$ value of the obtained PAdMA $\left(10.9 \mathrm{~kg} \mathrm{~mol}^{-1}\right)$ was the same as the $M_{\mathrm{n} \text {,theo }}$ value, and the $M_{\mathrm{w}} / M_{\mathrm{n}}$ value of 1.08 was less than that of PAdMA prepared by the $\mathrm{CuBr} / \mathrm{HMTETA}$ system. Thus, it was revealed that the $\mathrm{CuBr} / \mathrm{CuBr}_{2} / \mathrm{HMTETA}$ catalytic system is the most suitable for the ATRP of AdMA.

A kinetic investigation was subsequently carried out to confirm the controlled nature of the ATRP of AdMA using the $\mathrm{CuBr} / \mathrm{CuBr}_{2} /$ HMTETA catalytic system in toluene at $60^{\circ} \mathrm{C}$. Figure $2 \mathrm{a}$ shows the relationship between the monomer conversion of the polymerization and the $M_{\mathrm{n}}$ value of the obtained PAdMA. The $M_{\mathrm{n}}$ values of the product linearly increased with the increasing conversion of AdMA, and the $M_{\mathrm{w}} / M_{\mathrm{n}}$ value of 1.08-1.11 remained constant for up to at least $79 \%$ monomer conversion. Figure $2 \mathrm{~b}$ shows the first-order kinetic plot of the polymerization. The consumption rate of AdMA with increasing polymerization time was linear with the concentration of the
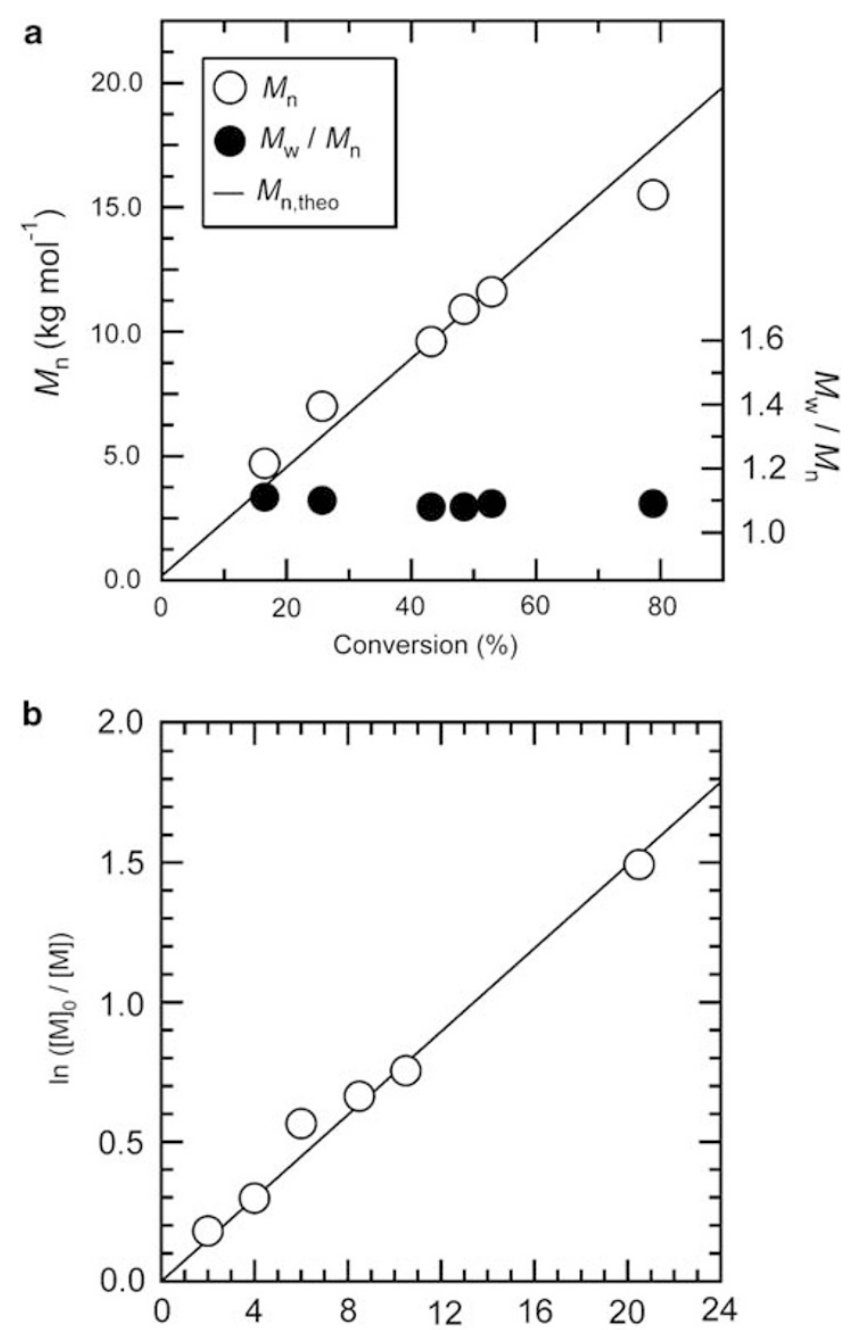

Time (h)

Figure 2 (a) Dependence of the number-average molecular weight $\left(M_{n}\right)$ and polydispersity $\left(M_{\mathrm{w}} / M_{\mathrm{n}}\right)$ on monomer conversion and (b) kinetic plots for the polymerization of AdMA catalyzed by $\mathrm{CuBr} / \mathrm{CuBr}_{2} / \mathrm{HMTETA}$ in toluene at $60{ }^{\circ} \mathrm{C}\left([\mathrm{AdMA}]_{0}=1.14 \mathrm{~mol} \mathrm{I}^{-1} \text {; }[\mathrm{AdMA}]_{0} /[\mathrm{MBiB}]_{0} /[\mathrm{CuBr}]_{0} / \mathrm{CuBr}_{2}\right]_{0} /$ $\left.[\text { HMTETA }]_{0}=100 / 1 / 1 / 0.2 / 1.2\right)$. remaining monomer in the reaction mixture. In conclusion, the ATRP system for AdMA was successfully established.

Moreover, we carried out the ATRP of AdMA in HFIP, a representative fluoroalcohol, to simultaneously control the molecular weight and tacticity ${ }^{15}$ of PAdMA (Scheme 1). The use of fluoroalcohols as the solvent for radical polymerization induces a tacticity change in the resultant polymer. $^{20,21}$ We also previously succeeded in the simultaneous control of the molecular weight and tacticity of PMMA by ATRP using HFIP. ${ }^{16,17}$ The ATRP of AdMA in HFIP was carried out using the $\mathrm{CuBr} / \mathrm{CuBr}_{2} / \mathrm{Me}_{6}$ TREN catalytic system at $20^{\circ} \mathrm{C}$ for $15 \mathrm{~h}$ (Supplementary Table S1, run 7) and at $-20^{\circ} \mathrm{C}$ for $40.5 \mathrm{~h}$ (Supplementary Table S1, run 11). Although the polymerization at $20^{\circ} \mathrm{C}$ yielded PAdMA with a broad $M_{\mathrm{w}} / M_{\mathrm{n}}$ value of 1.85 , the polymerization at $-20^{\circ} \mathrm{C}$ produced narrow-dispersed PAdMA with a $M_{\mathrm{w}} / M_{\mathrm{n}}$ ratio of 1.14 and $M_{\mathrm{n}}$ of $14.1 \mathrm{~kg} \mathrm{~mol}^{-1}$. The tacticity of PAdMA prepared in toluene at $60^{\circ} \mathrm{C}$ (Table 1, run 3) and in HFIP at $-20^{\circ} \mathrm{C}$ was compared. The triad tacticity of PAdMA can be analyzed from the resonance of the quaternary carbon in the adamantyl group appearing around $80-81$ p.p.m. in the ${ }^{13} \mathrm{C}$ NMR spectrum. ${ }^{5}$ Inversegated decoupling was applied to obtain the quantitative ${ }^{13} \mathrm{C} N M R$ spectra, which are shown in Supplementary Information (Supplementary Figure S1). The triad tacticity contents $(\mathrm{mm} / \mathrm{mr} / \mathrm{rr})$ of PAdMA prepared in toluene and HFIP were 4/27/69 and 1/21/78, respectively. The $r r$ triad contents of the PAdMA prepared in HFIP were $9 \%$ higher than that of the PAdMA prepared in toluene. Thus, the simultaneous control of the molecular weight and the tacticity of AdMA was also successfully achieved by polymerization in fluoroalcohol.

\section{Block copolymerization of AdMA and methyl methacrylate}

To use the controlled nature of the ATRP of AdMA, we first tried to prepare poly(1-adamantyl methacrylate)-block-poly(methyl methacrylate) (PAdMA- $b$-PMMA) from PAdMA with bromine end functionality $\left(M_{\mathrm{n}}=9.6 \mathrm{~kg} \mathrm{~mol}^{-1}, M_{\mathrm{w}} / M_{\mathrm{n}}=1.08\right)$, which was synthesized by the ATRP of AdMA using the $\mathrm{MBiB} / \mathrm{CuBr} / \mathrm{CuBr}_{2} / \mathrm{HMTETA}$-initiating system in toluene at $60^{\circ} \mathrm{C}$ for $6 \mathrm{~h}$ (Supplementary Scheme S1). However, PAdMA could not sufficiently initiate the block copolymerization of MMA using the $\mathrm{CuBr} / \mathrm{CuBr}_{2} / \mathrm{HMTETA}$ catalytic system in toluene at $60^{\circ} \mathrm{C}$ for $9 \mathrm{~h}$, resulting in the mixture of PAdMA- $b$-PMMA and unreacted PAdMA, as shown in Supplementary Information (Supplementary Figure S2). This result could be caused by the low reactivity of the PAdMA radical toward MMA, which was reported by Otsu et al. ${ }^{6}$

Thus, we changed the synthesis strategy, as shown in Scheme 2. The PMMA macroinitiator (PMMA-Br) was prepared by the ATRP of MMA using the MBiB/CuBr/HMTETA-initiating system. The resulting PMMA-Br had an $M_{\mathrm{n}}$ value of $9.9 \mathrm{~kg} \mathrm{~mol}^{-1}$ and an $M_{\mathrm{w}} / M_{\mathrm{n}}$ value of 1.15 (Figure 3a). The block polymerization of AdMA with PMMA$\mathrm{Br}$ was then carried out using the $\mathrm{CuBr} / \mathrm{CuBr}_{2} / \mathrm{HMTETA}$ catalytic system in toluene at $60{ }^{\circ} \mathrm{C}$ under the condition of $[\text { AdMA }]_{0} /[\mathrm{PMMA}-$ $\mathrm{Br}]_{0} /[\mathrm{CuBr}]_{0} /\left[\mathrm{CuBr}_{2}\right]_{0} /[\mathrm{HMTETA}]_{0}=76 / 1.0 / 0.74 / 0.16 / 0.90$ (Table 2, run 5). Although the obtained block copolymer, PMMA- $b$-PAdMA, showed a relatively narrow and unimodal SEC trace for the $M_{\mathrm{w}} / M_{\mathrm{n}}$ value of 1.18 and the observed $M_{\mathrm{n}}$ value agreed with the theoretical value, the monomer conversion of $24.7 \%$ was very low for the polymerization time of $9 \mathrm{~h}$.

Given those results, we applied the AGET ATRP method ${ }^{22}$ for the block copolymerization of AdMA with PMMA-Br (Scheme 2). Polymerization was carried out under the condition of $[\mathrm{AdMA}]_{0} /[\mathrm{PMMA}-$ $\mathrm{Br}]_{0} /\left[\mathrm{CuBr}_{2}\right]_{0} /[\mathrm{HMTETA}]_{0} /\left[\mathrm{Sn}(\mathrm{EH})_{2}\right]_{0}=73 / 1.0 / 0.73 / 0.73 / 0.33$ in toluene at $60^{\circ} \mathrm{C}$ (Table 2, run 6). The molecular weight of PMMA$b$-PAdMA increased with polymerization time, as shown in Figure 3. 
The obtained block polymers however showed bimodal SEC traces for polymerization times greater than $3 \mathrm{~h}$ (Figures $3 \mathrm{~d}$ and e). However, the SEC trace of the block polymer for $2 \mathrm{~h}$ is unimodal and the $M_{\mathrm{w}} / M_{\mathrm{n}}$ value was 1.13 (Figure $3 \mathrm{c}$ ). The $M_{\mathrm{n}}$ value of $18.7 \mathrm{~kg} \mathrm{~mol}^{-1}$ agreed with the predicted value. These results indicate that the AGET ATRP method was effective for the block copolymerization of AdMA using the PMMA macroinitiator.

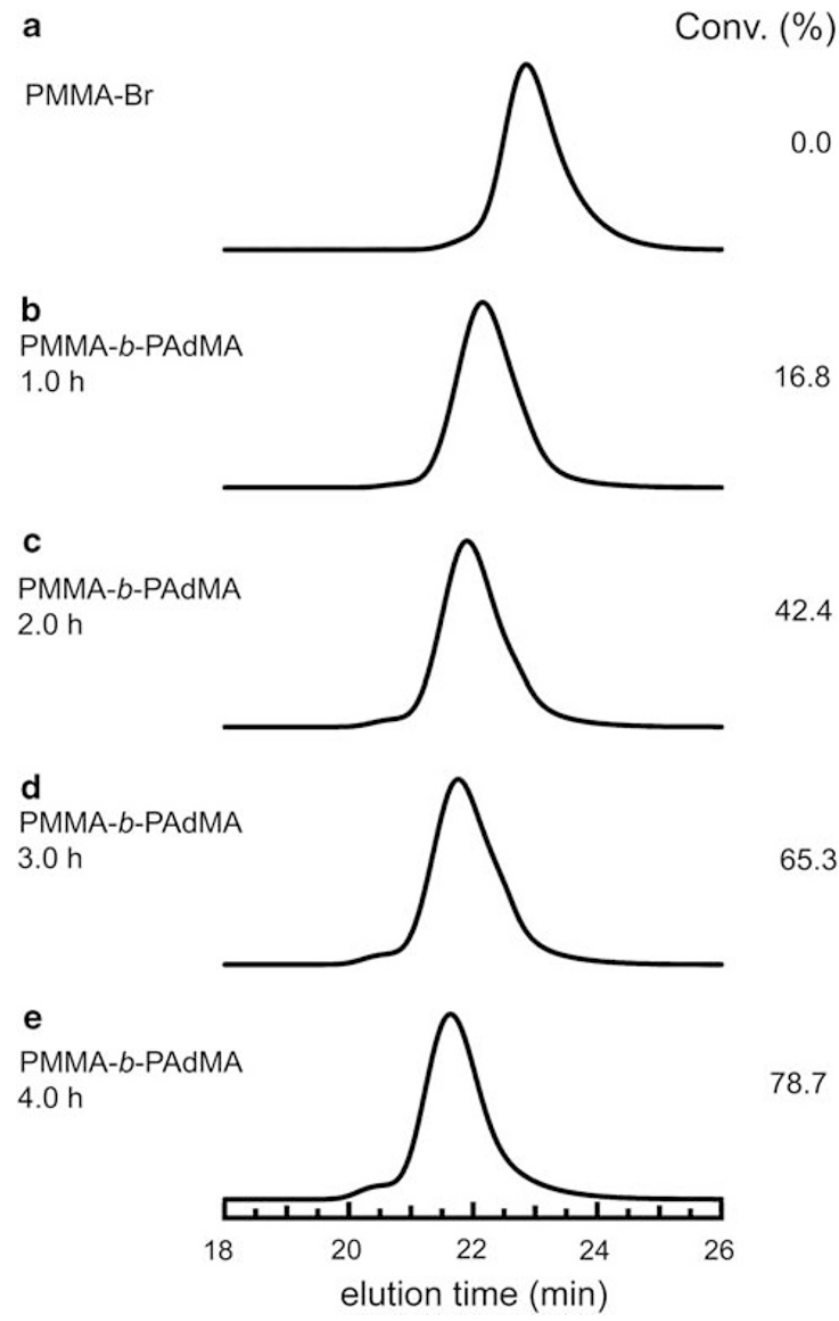

Figure 3 SEC traces of the (a) PMMA macroinitiator (PMMA-Br) and PMMA$b$-PAdMA obtained by the AGET ATRP of AdMA using PMMA-Br in toluene at $60^{\circ} \mathrm{C}$ after (b) $1 \mathrm{~h}$, (c) $2 \mathrm{~h}$, (d) $3 \mathrm{~h}$ and (e) $4 \mathrm{~h}$ ([AdMA $]_{0} /[\mathrm{PMMA}-\mathrm{Br}]_{0} /$ $\left.\left[\mathrm{CuBr}_{2}\right]_{0} /[\mathrm{HMTETA}]_{0} /\left[\mathrm{Sn}(\mathrm{EH})_{2}\right]_{0}=73 / 1.0 / 0.73 / 0.73 / 0.33\right)$.
Molecular weight and tacticity effect on the thermal properties of PAdMA

The thermal properties of polymers containing the adamantyl group were intensively investigated from the viewpoint of high thermal stability. We first investigated the relationship between the glass transition temperature $\left(T_{\mathrm{g}}\right)$ of PAdMA and its molecular weight. The $T_{\mathrm{g}}$ of each polymer was measured by DSC. Figure 4 shows the change in $T_{\mathrm{g}}$ of PAdMA with increasing $M_{\mathrm{n}}$, and the representative DSC trace is shown in Supplementary Information (Supplementary Figure S3). The $T_{\mathrm{g}}$ value varied within the range of $200-244^{\circ} \mathrm{C}$, with an increase in molecular weight from 4.6 to $32.1 \mathrm{~kg} \mathrm{~mol}^{-1}$. Although the previously reported PAdMA showed no glass transition in almost all cases, ${ }^{4-6}$ all the PAdMAs prepared by ATRP in this study showed glass transitions, presumably because of the low molecular weights obtained. The effect of tacticity on the $T_{\mathrm{g}}$ of PAdMA was investigated next. PAdMA with a $69 \% \mathrm{rr}$ triad content $\left(M_{\mathrm{n}}=14.5 \mathrm{~kg} \mathrm{~mol}^{-1}, M_{\mathrm{w}} /\right.$ $M_{\mathrm{n}}=1.12$ ) showed a $T_{\mathrm{g}}$ of $230^{\circ} \mathrm{C}$. However, PAdMA with a $78 \% \mathrm{rr}$ triad content $\left(M_{\mathrm{n}}=14.1 \mathrm{~kg} \mathrm{~mol}^{-1}, M_{\mathrm{w}} / M_{\mathrm{n}}=1.14\right)$ showed a $T_{\mathrm{g}}$ of $243^{\circ} \mathrm{C}$. Although these two polymers had narrow molecular weight distributions and almost the same molecular weight, the difference in their glass transition temperatures was large. This result indicates that the $T_{\mathrm{g}}$ of PAdMA increases with the increasing $r r$ triad contents, corresponding to the results reported by Otsu et al. ${ }^{5}$ The relationship between tacticity and the $T_{\mathrm{g}}$ of PAdMA was the same as the relationship for PMMA. ${ }^{23}$

\section{Conclusions}

The controlled/living polymerization system for AdMA was successfully established by the ATRP method using $\mathrm{CuBr} / \mathrm{CuBr}_{2} / \mathrm{HMTETA}$.

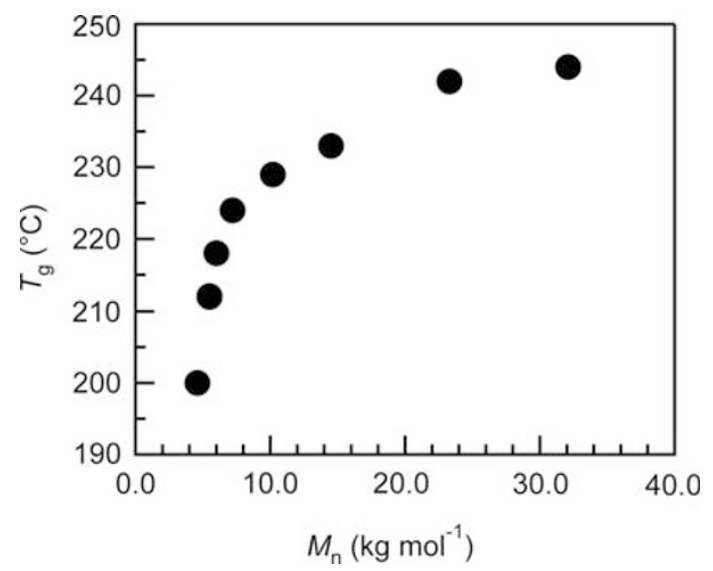

Figure 4 Dependence of the glass transition temperature $\left(T_{\mathrm{g}}\right)$ on the $M_{\mathrm{n}}$ of PAdMA $(\mathrm{mm} / \mathrm{mr} / \mathrm{rr}=4 / 27 / 69)$.

Table 2 Synthesis of PMMA-b-PAdMA by block polymerization of AdMA using the PMMA macroinitiator (PMMA-Br) in toluene at $60{ }^{\circ} \mathrm{C}$

\begin{tabular}{|c|c|c|c|c|c|c|}
\hline \multirow[b]{2}{*}{ Run } & \multirow[b]{2}{*}{ Initiating system and reaction condition (molar ratio) } & \multirow[b]{2}{*}{ Time $(h)$} & \multirow[b]{2}{*}{ Conv. $(\%)^{a}$} & \multicolumn{2}{|c|}{$\mathrm{M}_{n}\left(\mathrm{~kg} \mathrm{~mol}^{-1}\right)$} & \multirow[b]{2}{*}{$\mathrm{M}_{w} \mathrm{M}_{n}^{\mathrm{b}}$} \\
\hline & & & & Theo. $^{\mathrm{c}}$ & Obsd. & \\
\hline 5 & {$[\mathrm{AdMA}]_{0} /[\mathrm{PMMA}-\mathrm{Br}]_{0} /[\mathrm{CuBr}]_{0} /\left[\mathrm{CuBr}_{2}\right]_{0} /[\mathrm{HMTETA}]_{0}(76 / 1.0 / 0.74 / 0.16 / 0.90)^{\mathrm{d}}$} & 9.0 & 24.7 & 14.0 & 15.5 & 1.18 \\
\hline 6 & {$[\mathrm{AdMA}]_{0} /[\mathrm{PMMA}-\mathrm{Br}]_{0} /[\mathrm{CuBr}]_{0} /[\mathrm{HMTETA}]_{0} /\left[\mathrm{Sn}(\mathrm{EH})_{2}\right]_{0}(73 / 1.0 / 0.73 / 0.73 / 0.33)^{\mathrm{e}}$} & 2.0 & 42.4 & 16.7 & 18.7 & 1.13 \\
\hline
\end{tabular}

PMMA-Br; $M_{\mathrm{n}}=9.9 \mathrm{~kg} \mathrm{~mol}^{-1}$ and $M_{\mathrm{w}} / M_{\mathrm{n}}=1.15$.

a Determined by GC from the concentration of residual monomer with toluene as the internal standard.

betermined by SEC using PMMA standards in $\mathrm{CHCl}_{3}$.

${ }^{c}$ Calculated from $[\mathrm{AdMA}]_{0} /[\mathrm{PMMA}-\mathrm{Br}]_{0} \times$ conv. $\times(\mathrm{M}$. W. of $\mathrm{AdMA}=220.31)+($ M.W. of PMMA-Br=9900).

${ }^{c}$ Calculated from $[$ AdMA
${ }^{\mathrm{d}}[\mathrm{AdMA}]_{0}=1.14 \mathrm{~mol} \mathrm{I}^{-1}$

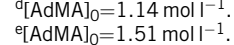


The simultaneous control of the tacticity and molecular weight of PAdMA was achieved by ATRP conducted in HFIP at low temperature using the $\mathrm{CuBr} / \mathrm{CuBr}_{2} / \mathrm{Me}_{6} \mathrm{TREN}$ catalytic system. In addition, the block copolymerization of AdMA with MMA proceeded reasonably using the PMMA macroinitiator/ $\mathrm{CuBr}_{2} / \mathrm{HMTETA} / \mathrm{Sn}(\mathrm{EH})_{2}$-initiating system based on the AGET ATRP method. The dependence of the glass transition temperature of PAdMA on molecular weight and tacticity was clearly revealed by DSC analyses.

\section{ACKNOWLEDGEMENTS}

This study was partly supported by a Grant-in-Aid for the Japan Society for the Promotion of Science (JSPS) Fellows, and by the Global COE Program (Catalysis as the Basis for Innovation in Materials Science) of the Ministry of Education, Culture, Sports, Science and Technology.

1 Matsumoto, A., Mizuta, K. \& Otsu, T. Synthesis and the thermal properties of poly(cycloalkyl methacrylate)s bearing bridged- and fused-ring structures. J. Polym. Sci., Part A: Polym. Chem. 31, 2531-2539 (1993).

2 Yu, J.- M., Dubois, Ph. \& Jérôme, R. Synthesis and properties of poly[isobornyl methacrylate (IBMA)- $b$-butadiene (BD)- $b$-IBMA] copolymers: new thermoplastic elastomers of a large service temperature range. Macromolecules 29, 7316-7322 (1996).

3 Yu, J.- M., Dubois, Ph. \& Jérôme, R. Poly[poly(isobornyl methacrylate-co-methyl methacrylate) (poly(IBMA-co-MMA))- $b$-polybutadiene- $b$-poly(IBMA-co-MMA)] copolymers: synthesis, morphology, and properties. Macromolecules 30, 6536-6543 (1997).

4 Ishizone, T., Tajima, H., Torimae, H. \& Nakahama, S. Anionic polymerizations of 1adamantyl methacrylate and 3-methacryloyloxy-1,1'-biadamantane. Macromol. Chem. Phys. 203, 2375-2384 (2002).

5 Matsumoto, A., Tanaka, S. \& Otsu, T. Synthesis and characterization of poly(1-adamantyl methacrylate): effects of the adamantyl group on radical polymerization kinetics and thermal properties of the polymer. Macromolecules 24, 4017-4024 (1991).

6 Otsu, T., Matsumoto, A., Horie, A. \& Tanaka, S. Synthesis of thermally stable vinyl polymers from adamantyl-containing acrylic derivatives. Chem. Lett. 1145-1148 (1991).

7 Kavitha, A. A. \& Singha, N. K. High temperature resistant tailor-made poly(meth)acrylates bearing adamantyl group via atom transfer radical polymerization. J. Polym. Sci., Part A: Polym. Chem. 46, 7101-7113 (2008).

8 Acar, H. Y. Jensen, J. J., Thigpen, K., McGowen, J. A. \& Mathias, L. J. Evaluation of the spacer effect on adamantane-containing vinyl polymer $T_{\mathrm{g}}$ 's. Macromolecules 33 , 3855-3859 (2000).
9 Sinkel, C., Agarwal, S., Fokina, N. A. \& Schreiner, P. R. Synthesis, characterization, and property evaluations of copolymers of diamantyl methacrylate with methyl methacrylate. J. Appl. Polym. Sci. 114, 2109-2115 (2009).

10 Kavitha, A. A. \& Singha, N. K. Tailor-made poly(methyl acrylate) bearing amantadine functionality (amino adamantyl) via atom transfer radical polymerization (ATRP). A precursor of a supramolecular cross-linked polymer. Macromolecules 42, 5499-5508 (2009).

11 Lou, Q., Kishpaugh, M. A. \& Shipp, D. A. Synthesis of statistical and block copolymers containing adamantyl and norbornyl moieties by reversible addition-fragmentation chain transfer polymerization. J. Polym. Sci., Part A: Polym. Chem. 48, 943-951 (2010).

12 Hawker, C. J., Bosman, A. W. \& Harth, E. New polymer synthesis by nitroxide mediated living radical polymerizations. Chem. Rev. 101, 3661-3688 (2001).

13 Matyjaszewski, K. \& Xia, J.- H. Atom transfer radical polymerization. Chem. Rev. 101, 2921-2990 (2001).

14 Moad, G., Rizzardo, E. \& Thang, S. H. Living radical polymerization by the RAFT process - a second update. Aust. J. Chem. 62, 1402-1472 (2009).

15 Satoh, K. \& Kamigaito, M. Stereospecific living radical polymerization: dual control of chain length and tacticity for precision polymer synthesis. Chem. Rev. 109, 5120-5156 (2009).

16 Miura, Y., Satoh, T., Narumi, A., Nishizawa, O., Okamoto, Y. \& Kakuchi, T. Atom transfer radical polymerization of methyl methacrylate in fluoroalcohol: simultaneous contorol of molecular weight and tacticity. Macromolecules 38, 1041-1043 (2005).

17 Miura, Y., Satoh, T., Narumi, A., Nishizawa, O., Okamoto, Y. \& Kakuchi, T. Synthesis of well-defined syndiotactic poly(methyl methacrylate) with low-temperature atom transfer radical polymerization in fluoro alcohol. J. Polym. Sci., Part A: Polym. Chem. 44, 1436-1446 (2006)

18 Matyjaszewski, K., Davis, K., Patten, T. E. \& Wei, M.- L. Observation and analysis of a slow termination process in the atom transfer radical polymerization of styrene. Tetrahedron 53, 15321-15329 (1997).

19 Wang, J.- L., Grimaud, T. \& Matyjaszewski, K. Kinetic study of the homogenous atom transfer radical polymerization of methyl methacrylate. Macromolecules 30, 6507-6512 (1997).

20 Isobe, Y., Yamada, K., Nakano, T. \& Okamoto, Y. Stereospecific free-radical polymerization of methacrylates using fluoroalcohols as solvents. Macromolecules 32, 5979-5981 (1999).

21 Isobe, Y., Yamada, K., Nakano, T. \& Okamoto, Y. Stereocontrol in the free-radical polymerization of methacrylates with fluoroalcohols. J. Polym. Sci., Part A: Polym. Chem. 38, 4693-4703 (2000).

22 Jakubowski, W. \& Matyjaszewski, K. Activator generated by electron transfer for atom transfer radical polymerization. Macromolecules 38, 4139-4146 (2005).

23 Kitayama, T., Ute, K., Yamamoto, M., Fujimoto, N. \& Hatada, K. Highly isotactic and living polymerization of ethyl methacrylate with $t-\mathrm{C}_{4} \mathrm{H}_{9} \mathrm{MgBr}$ in toluene and the preparation of block and random copolymers with high stereoregularity. Polym. J. 22, 386-396 (1990).

Supplementary Information accompanies the paper on Polymer Journal website (http://www.nature.com/pj) 